\title{
Vitamin A deficiency in Bangladesh: a review and recommendations for improvement
}

\author{
Faruk Ahmed* \\ Institute of Nutrition and Food Science, University of Dhaka, Dhaka-1000, Bangladesh
}

Submitted 28 July 1998: Accepted 4 November 1998

\begin{abstract}
Objective: This article provides a comprehensive review of the change in vitamin A status and the extent of vitamin A deficiency among different population groups in Bangladesh up to the present time. The result of experience with different strategies and interventions designed to improve vitamin A status are then reviewed, leading to a discussion of key options for action, as well as important areas for research and evaluation.

Design and setting: All the available data have been examined in detail, including data from nationally representative samples and nationwide surveys, as well as small studies in different population groups. Reports on the effectiveness of different intervention programmes have been used.

Results: Over the past three decades a number of studies, which include national nutrition surveys, have been carried out to investigate the prevalence of vitamin A deficiency among different population groups in Bangladesh, and they have demonstrated a significant public health problem. Studies have shown that the prevalence of severe deficiency, based on the prevalence of night blindness in preschool children, decreased from $3.6 \%$ in $1982-83$ to $1.78 \%$ in 1989 and $0.6 \%$ in 1996. However, there is still a high prevalence of subclinical vitamin A deficiency, based on the biochemical assessment of serum retinol levels in preschool children, estimated mainly from hospital-based groups. Night blindness and Bitot's spot are also found to exist among school-age children and adolescents. Recent reports indicate that night blindness among rural mothers is as high as $1.4 \%$. Only a limited number of studies, with small sample sizes, are available where serum retinol has been reported for school-age children, adolescents and pregnant women. Nevertheless, these studies confirm the presence of low levels of serum retinol and hence, the existence of subclinical vitamin A deficiency. Furthermore, the dietary intake of vitamin A in each population group has been found to be less than the Recommended Daily Allowance (RDA), indicating a significant risk of deficient intakes of vitamin A.

To address the problem of vitamin A deficiency, the government of Bangladesh started the Nutritional Blindness Programme in 1973. The main activities of the programme include vitamin A capsule (VAC) supplementation to children of 6 months to 6 years old, nutrition education to increase the production and consumption of vitamin A rich foods, and training of primary health-care workers on the clinical diagnosis and treatment of vitamin A deficiency, VAC distribution and nutrition education. Since 1988, as a long-term strategy, Helen Keller International has been implementing community home gardening promotion projects. To date, the possibility that foods may be fortified with vitamin $\mathrm{A}$, has not been explored as a possible approach in Bangladesh.

Conclusion: Although short- to long-term prevention and control programmes are to some extent in place, to improve the situation of vitamin A deficiency, Bangladesh needs a more appropriate mix of interventions for the entire population. More operational research and evaluation are needed if a fully effective programme to alleviate the problem of vitamin A deficiency is to be developed. Finally, to achieve the goal of virtual elimination of vitamin A deficiency will require an integrated approach which brings together appropriate actions at every level, within and across the many sectors of society.
\end{abstract}

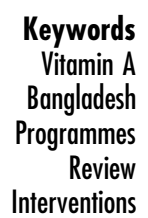


The term 'vitamin A' is the generic descriptor for a group of chemical compounds known as retinoids exhibiting qualitatively the biological activity of retinol. They include retinol, its ester (retinyl palmitate) and retinoic acid. Vitamin A is a fat-soluble substance found in ester form in animal and dairy products and it is hydrolysed in the intestinal cells to form retinol. Carotene, the naturally occurring progenitor of vitamin A found in certain vegetables and fruits, is split in cells of the small intestine to retinaldehyde, most of which is readily converted to retinol.

Vitamin $\mathrm{A}$ is an essential nutrient needed in small amounts for normal cellular function, and is especially required for the visual system, growth and development, maintenance of epithelial cellular integrity, immune function and reproduction ${ }^{1}$. Vitamin A deficiency occurs when body stores are depleted to the extent that normal physiological function is impaired even though at this stage overt clinical deficiency, such as eye signs, may not be evident. Depletion of stored vitamin A is usually seen as the consequence of an inadequate dietary intake of the vitamin itself over a period of time, although losses may be increased in association with infection. The level of depletion at which physiological functions begin to be impaired is not entirely clear. What is known, however, is that the vitamin is extensively recycled between the plasma, liver and other tissues. It appears that the rate of utilization by specific tissues can show some adaptation to diminishing availability. This adaptation and recycling may serve to maintain relatively constant levels in the blood until body stores become depleted below a critical point, exceeding the capacity of homeostatic mechanisms to the point where adaptation can no longer compensate ${ }^{2}$.

Severe vitamin A deficiency has long been recognized as a potentially lethal, but preventable nutritional disease. However, the extent to which a large proportion of the population might be affected by less severe forms of deficiency and the implications of this for survival and health have only been realized recently. Basic research has now demonstrated the underlying cellular processes through which a deficiency of vitamin A can have far-reaching effects which would predispose to a range of disordered function, including effects on the intestine, respiratory tract and immune system, as well as involvement of the eyes ${ }^{3}$.

The assessment of vitamin A status depends on the validity and interpretation of the measures employed which include clinical assessment based upon ocular signs and the biochemical determination of the concentration of metabolites in blood. There is a standard classification system for ocular indicators of vitamin A deficiency, and minimum prevalence criteria for interpretation to identify a public health problem have been recommended by the World Health Organization (WHO) Expert Group on the control of vitamin A deficiency and xerophthalmia (Table 1$)^{4}$. Serum retinol levels, while not considered a reliable index of subclinical vitamin A status of individuals, has proven to be a useful indicator for estimating the relative risk and prevalence of severity and its magnitude as subclinical problem at a population level. A prevalence above $5 \%$ for values of serum retinol $<0.35 \mu \mathrm{moll}^{-1}$ has been used globally to define a deficient population and as corroborative evidence with clinical eye signs for defining the risk of blinding malnutrition ${ }^{4}$. This cut-off point is, however, insufficient to assess the prevalence of risk of vitamin A deficiency at the subclinical level. In the 1980s it became evident that subclinical deficiency was associated with a significant increase in child mortality and this realization provided the impetus for the assessment of vitamin A status at the subclinical level. The WHO 1996 report proposed cut-off points for various biological indicators and suggested that a public health problem exists when, for the criteria set in Table 2, at least two of the indicators are met $^{5}$. In addition there are a number of ecological indicators that can also be used to identify vitamin A deficiency as a public health problem 5 .

It is now estimated that vitamin A deficiency, including subclinical and clinical forms of severe and moderate degrees of public health significance, exists in more than 60 countries. Worldwide, an estimated 2.8 million children $0-4$ years of age are clinically affected by vitamin A deficiency, and 251 million more are severely or moderately subclinically deficient. Thus,

\begin{tabular}{lc}
$\begin{array}{l}\text { Table } 1 \text { Criteria for assessing the public health significance of xerophthalmia and vitamin A } \\
\text { deficiency, based on the prevalence among children less than } 6 \text { years old in the community }\end{array}$ \\
\hline Criteria & $\begin{array}{c}\text { Minimum prevalence } \\
(\%)\end{array}$ \\
\hline Clinical (primary) & 1.0 \\
Night blindness (XN) & 0.5 \\
Bitot's spot (XIB) & 0.01 \\
Corneal xerosis and/or ulceration/keratomalacia (X2 + X3A + X3B) & 0.05 \\
Xerophthalmia-related corneal scars (XS) & \\
Biochemical (supportive) & 5.0 \\
Serum retinol (vitamin A) less than $0.35 \mu \mathrm{molI}^{-1}$ & \\
\hline
\end{tabular}


Table 2 Biological indicators of subclinical vitamin A deficiency in children 6-71 months of age ${ }^{5}$

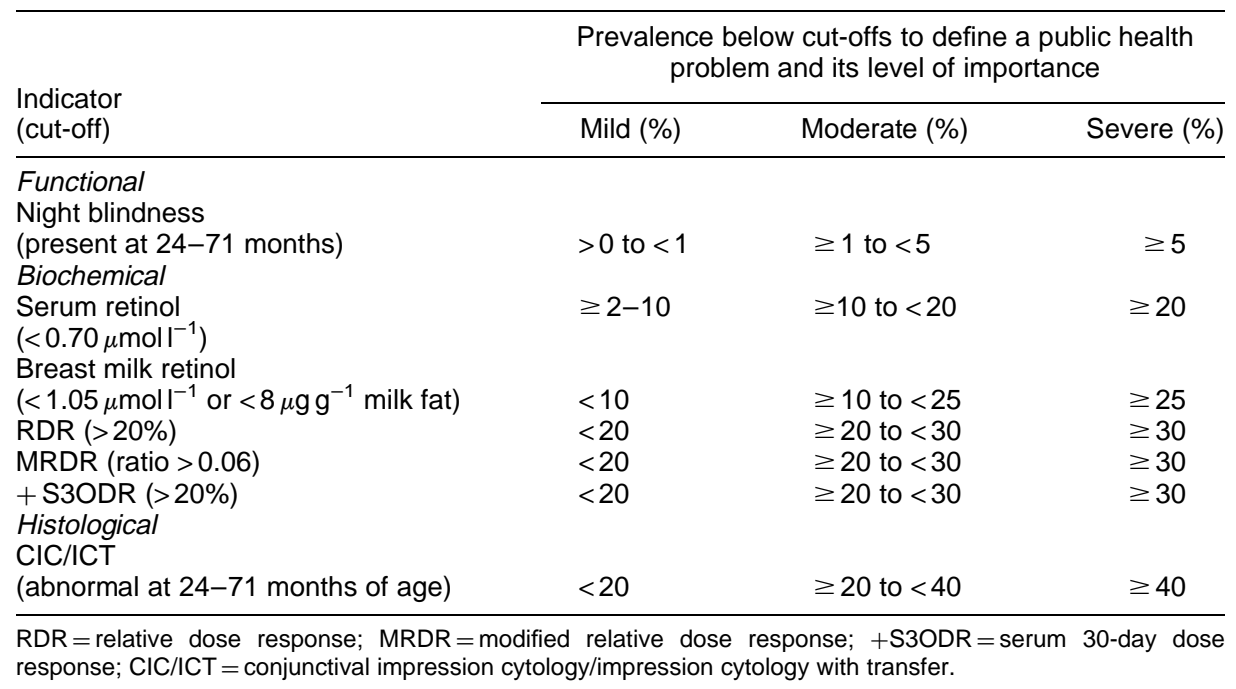

at least 254 million preschool children are 'at risk' in terms of their health and survival ${ }^{6}$. The majority of these children live in Asia, which houses over half of the world's population, and especially in the countries within the south-east Asian and western Pacific regions ${ }^{7}$. Although the prevalence of severe clinical vitamin A deficiency declines with age, less severe vitamin A deficiency is frequently found in adolescence and amongst young adults, where the prevalence of mild xerophthalmia may exceed the rates in preschool children ${ }^{8,9}$. Vitamin A deficiency may also be found among adults, especially in women of reproductive age ${ }^{10,11}$.

Bangladesh is a tropical developing country of about 124 million people with a growth rate of $1.8 \%$. It has one of the highest population densities of 861 persons $\mathrm{km}^{-212}$. About $80 \%$ of the population live in the rural area and about 50\% subsist below the poverty line ${ }^{12}$. Bangladesh is vulnerable and experiences frequent natural disaster; flood, drought, cyclones and tornadoes. According to 1995 estimates, the infant mortality rate and under 5 mortality rate are 85 and $115 / 1000$ live birth ${ }^{13}$.

Vitamin A deficiency has long been identified as a serious public health problem in Bangladesh. In this article the present situation is reviewed comprehensively to identify the vitamin A status and frequency of deficiency among different population groups in Bangladesh. There is a focus on the present policies and programmes aimed at improving the situation, an assessment of the achievements in controlling deficiency and an indication of possible constraints in the complete eradication of vitamin A deficiency. Furthermore, there is an outline of specific needs and key options for action and the priority areas for future operations research to improve the situation. The data presented here are not all based on representative national sampling. Rather, the review has drawn upon all published papers, reports and documents made available over the last 25 years. Furthermore, age- and sex-specific evaluation of the available data is provided to help in the understanding of the magnitude of the problem and to assist the reader in interpreting the prevalence data.

\section{Situation assessment and analysis}

At the time of the first national nutrition survey in 1962-64 (when the country was known as East Pakistan) $0.2 \%$ of the total population were found to have Bitot's spots, and $4.2 \%$ conjunctival xerosis ${ }^{14}$. In 1972, following the War of Liberation, refugees were initially settled in rehabilitation camps on their return from India. A survey conducted by WHO amongst the children in the camps revealed a high prevalence of vitamin A deficiency, especially the problem of xerophthalmia ${ }^{15}$. The second national nutrition survey in 1975-76 showed that $1 \%$ of the total population had night blindness, $0.6 \%$ had Bitot's spots and $11.7 \%$ had conjunctival xerosis ${ }^{16}$. In 1981-82, the third survey also reported a similarly high prevalence of vitamin A deficiency in the Bangladeshi population ${ }^{17}$. In 1982-83, the first population-based assessment of the magnitude of vitamin A deficiency in Bangladesh was conducted by Helen Keller International (HKI) and the Institute of Public Health Nutrition (IPHN) ${ }^{18}$. The study indicated that each year more than 900,000 children under 6 years of age were suffering from some degree of xerophthalmia and 30,000 or more children became permanently blind ${ }^{18}$.

The three successive national nutrition surveys (1962-64, 1975-76 and 1981-82) in Bangladesh were all conducted with a special emphasis on the dietary intake and repeatedly reported an insufficient intake of vitamin A. In 1975-76 the average vitamin A intake was only $36 \%$ of the recommended intake, a substantial drop from the 93\% reported in the 1962-64 survey ${ }^{14,16}$. 
The situation was found to be basically unchanged in the 1981-82 survey where $89 \%$ of the household members did not meet the Recommended Daily Allowance (RDA), with the average intake being only $38 \%$ of the requirement ${ }^{17}$. In the last two surveys, the vitamin A requirements for different age and sex groups were calculated, based upon the criteria of WHO $1974^{16,17}$. The data revealed that no significant progress had been made in the vitamin A intake of the Bangladeshi population. In the largely rural environment of Bangladesh approximately $90 \%$ of the dietary vitamin $\mathrm{A}$ is in the form of carotenoids, which comes from vegetables and fruits ${ }^{17}$. As with other micronutrients various social and economic factors contribute to the inadequate intake.

For all the surveys at the national level clinical examination and the identification of signs of deficiency was the primary way in which vitamin A status was assessed in the rural population, and therefore only the more severe and clinically evident deficiency could be detected. In addition, there have been a number of studies which have been carried out using biochemical indicators to investigate vitamin A status in different population groups. Not all studies have been in groups or populations which are nationally representative, nevertheless, the information is of considerable value in indicating the magnitude of the problem and especially in providing an indication of the frequency of subclinical deficiency. Where possible the magnitude of the problem has been categorized in relation to population groups, related to their different needs and requirements, by age, sex and physiological state.

\section{Infants and preschool children}

A summary of the major findings on the prevalence of vitamin A deficiency based on ocular signs and symptoms in preschool children are shown in Table 3. The survey of 1975-76, indicated a prevalence of 1.3\% for night blindness in children aged $1-4$ years ${ }^{16}$, which decreased to $0.6 \%$ in $1981-82^{17}$. By contrast, the prevalence of conjunctival xerosis found in 1981-82 was nearly double that in 1975-76 $6^{16,17}$. The Bangladesh Nutritional Blindness study of 1982-83 revealed that, for children aged 6-59 months, 3.6\% in rural areas and $2.8 \%$ in urban slums had night blindness. These rates are much greater than the minimum criteria required by the WHO classification as necessary for the definition of a major public health problem ${ }^{18}$. The prevalence of conjunctival xerosis was $2.0 \%$ in rural children and $2.5 \%$ in urban slum children. The prevalence of Bitot's spots was 0.9 and $1.6 \%$ for the rural and urban slum children, respectively ${ }^{18}$. The Nutritional Blindness Prevention Programme Evaluation Report for 1989 indicated that the prevalence of night blindness among preschool children had decreased to $1.78 \%$, from $3.6 \%$ in $1982-83^{19}$. The prevalence of night blindness was found to be higher in female children (1.97\%) than male children $(1.59 \%)^{19}$.

In the 1980s, beside national surveys, a number of studies have also investigated the prevalence of vitamin A deficiency in preschool children. A study in a rural population of Comilla district showed that overall incidence of xerophthalmia in children aged 0-6 years was 4.7 and 3.0/1000 in males and females, respectively ${ }^{20}$. In coastal villages of Bhola district it was found that the prevalence of night blindness in preschool children was $4.1 \%{ }^{21}$. Saha et al. ${ }^{22}$ showed that for preschool children in areas with a safe water supply $(n=89)$ the prevalence of night blindness was $1.1 \%, 10.1 \%$ had conjunctival xerosis and none had Bitot's spots. This contrasted with preschool children in the areas with no safe water supply $(n=68)$, where none had night blindness and 12\% had conjunctival xerosis, but nearly $1.5 \%$ had Bitot's spots ${ }^{22}$. For a clinic-based study of 22,407 preschool children about $1 \%$ had night blindness and $2.0 \%$ conjunctival xerosis with Bitot's spot ${ }^{23}$. The effect of breast feeding on the risk of xerophthalmia was studied in 2687 children aged 6 months to 3 years attending a local hospital during 1983-85 and showed that about 2.1\% had

Table 3 Summary of vitamin A deficiency prevalence data based on ocular signs and symptoms in preschool children of Bangladesh

\begin{tabular}{|c|c|c|c|c|c|c|c|c|c|}
\hline Reference & Area & Place & Setting & $\begin{array}{l}\text { Study } \\
\text { period }\end{array}$ & Age group & $\begin{array}{l}\text { Sample } \\
\text { size }\end{array}$ & $\begin{array}{c}\text { Night } \\
\text { blindness } \\
(\%)\end{array}$ & $\begin{array}{c}\text { Bitot's } \\
\text { spot } \\
(\%)\end{array}$ & $\begin{array}{c}\text { Corneal } \\
\text { xerosis } \\
(\%)\end{array}$ \\
\hline INFS $^{16}$ & Rural & 12 sites & Community & $1975-76$ & $0-4$ years & 469 & 1.3 & 0.0 & 9.8 \\
\hline INFS $^{17}$ & Rural & 12 sites & Community & $1981-82$ & $0-4$ years & 514 & 0.6 & 0.3 & 17.6 \\
\hline $\mathrm{HKI} / \mathrm{IPHN}^{18}$ & $\begin{array}{l}\text { Rural }(R) \\
\quad \& \text { urban } \\
\text { slum }(U)\end{array}$ & 100 sites & Community & 1982-83 & 3-71 months & $\begin{array}{l}R=18,660 \\
U=3675\end{array}$ & $\begin{array}{l}\mathrm{R}=3.8 \\
\mathrm{U}=2.8\end{array}$ & $\begin{array}{l}\mathrm{R}=0.9 \\
\mathrm{U}=1.6\end{array}$ & $\begin{array}{l}\mathrm{R}=2.0 \\
\mathrm{U}=2.5\end{array}$ \\
\hline IPHN/UNICEF ${ }^{19}$ & Rural & 40 Upazila* & Community & 1989 & $6-71$ months & 4611 & 1.78 & n.a. & n.a. \\
\hline Sikder et al. ${ }^{23}$ & Periurban & Dhaka & Hospital & $1981-85$ & $<5$ years & 22,407 & 1.0 & 2.0 & 0.2 \\
\hline Mahalanabis $^{24}$ & Urban & Dhaka & Hospital & $1983-85$ & $6-36$ months & 2687 & 1.71 & 0.56 & 1.15 \\
\hline$\left.\mathrm{HK}\right|^{25}$ & Rural & 41 thana* & Community & Dec. 1996 & $6-59$ months & 16,140 & 0.60 & n.a. & n.a. \\
\hline
\end{tabular}

*Subdistrict.

n.a., not available; INFS, Institute of Nutrition and Food Science; HKI, Helen Keller International; IPHN, Institute of Public Health Nutrition. 
xerophthalmia ${ }^{24}$. However, recent reports of the Nutritional Surveillance Project of HKI indicate a significant decline in the prevalence of night blindness in rural children aged 24-59 months, varying between 0.6 and $0.8 \%$ by round of data collection. No cases of night blindness have been reported in urban children since $1995^{25}$.

The biochemical evidence for vitamin A deficiency in preschool children is limited, and mainly derived from hospital-based studies with small samples (Table 4). Brown et al. ${ }^{26}$ showed that $20 \%$ of rural children aged 1-6 years $(n=95)$ had levels of serum retinol (vitamin A) below $0.35 \mu \mathrm{moll}^{-1}$. The serum retinol concentrations in 30 children aged 1-10 years admitted to hospital for the treatment of diarrhoea ${ }^{27}$ were below $0.70 \mu \mathrm{moll}^{-1}$, with nearly two-thirds having levels below $0.35 \mu \mathrm{moll}^{-1}$. Two other studies have found that mean serum retinol level was less than $1.05 \mu \mathrm{moll}^{-1}$ in children admitted to hospital for the treatment of diarrhoea ${ }^{28,29}$. A hospital-based study of 183 healthy infants aged $6-17$ weeks ${ }^{30}$ showed that $35 \%$ had serum retinol level less than $0.35 \mu \mathrm{mol}^{-1}$, and $87 \%$ had levels below $0.70 \mu \mathrm{moll}^{-1}$. In a clinic-based study of 85 healthy infants aged 2-11 months ${ }^{31}, 56 \%$ had serum retinol levels less than $0.70 \mu \mathrm{moll}^{-1}$ and $18 \%$ had levels below $0.35 \mu \mathrm{moll}^{-1}$.

Only a limited number of studies have investigated the dietary intake of preschool children. The nutrition survey of 1975-76 showed that the average vitamin A intake of the children aged 1-6 years ranged from 30 to $50 \%$ of the $\mathrm{RDA}^{16}$ and it was $38-78 \%$ of the RDA in 1981-82 ${ }^{17}$. In a longitudinal study, Brown et al. ${ }^{32}$ investigated the food and nutrient consumption by 70 children aged between 5 and 30 months. They found that for the age group 5-17 months males met $92 \%$ and females met $67 \%$ of the RDA, whereas between 18 and 30 months of age males met $82 \%$ and females met $61 \%$ of the RDA ${ }^{32}$.

In summary, it is clear from the above studies that the prevalence of clinically evident vitamin A deficiency among preschool children in Bangladesh has decreased significantly over the past two decades and this decrease can be attributed largely to the high coverage of national VAC distribution programme ${ }^{25}$. However, there is ample biochemical evidence that subclinical vitamin A deficiency among preschool children remains a significant public health problem. Although the dietary intake appears to have improved over the period, it is still not adequate and falls far below the requirement.

\section{School-age children and adolescents}

The prevalence of night blindness and Bitot's spots among boys and girls, aged 5-14 years, was found to have decreased in 1981-82 compared to $1975-76^{16,17}$. However, the prevalence was higher in boys than girls $^{16,17}$. The prevalence of conjunctival xerosis was also found to be higher in boys (32.1\%) than girls $(22.7 \%)^{17}$. Khan et al. ${ }^{20}$ showed that the incidence of xerophthalmia was 5.0/1000 in males aged 7-19 years; $1.7 / 1000$ in females. Saha et al $^{22}$ found that about $1.4 \%$ of the male $(n=146)$ aged $5-14$ years in areas with safe water supply and $7.9 \%$ of the same age group in areas with no safe water supply $(n=63)$ had night blindness. Among the females, it was $0.7 \%$ in areas with safe water supply $(n=144)$ and $1.4 \%$ in area with no safe water supply $(n=79)^{22}$. The overall prevalence of night blindness was lower in females compared with males $^{22}$. In 5420 children aged $0-15$ years in a northern district of Bangladesh the prevalence of night blindness was $1.9 \%{ }^{33}$.

Limited information is available for serum retinol levels among school-age children and adolescents (Table 5). In recent years we have conducted a series of studies in these population groups. In an urban population, assessed to be of middle to higher socioeconomic status ${ }^{34,35}$, we found that about $20 \%$ of 242 school children aged 5-12 years, and $11 \%$ of 225

Table 4 Summary of the prevalence data of serum retinol levels suggestive of a public health problem in preschool children in Bangladesh

\begin{tabular}{|c|c|c|c|c|c|c|c|c|c|c|}
\hline \multirow[b]{2}{*}{ Reference } & \multirow[b]{2}{*}{ Area } & \multirow[b]{2}{*}{ Place } & \multirow[b]{2}{*}{ Setting } & \multirow[b]{2}{*}{$\begin{array}{l}\text { Study } \\
\text { period }\end{array}$} & \multirow[b]{2}{*}{ Age group } & \multirow[b]{2}{*}{$\begin{array}{l}\text { Sample } \\
\text { size }\end{array}$} & \multirow{2}{*}{$\begin{array}{c}\text { Mean } \\
\text { serum } \\
\text { retinol } \\
\left(\mu \mathrm{moll}^{-1}\right)\end{array}$} & \multicolumn{3}{|c|}{$\begin{array}{l}\text { Serum retinol level } \\
\qquad\left(\mu \mathrm{moll}^{-1}\right)\end{array}$} \\
\hline & & & & & & & & $\begin{array}{c}<0.35 \\
(\%)\end{array}$ & $\begin{array}{c}<0.70 \\
(\%)\end{array}$ & $\begin{array}{l}<1.05 \\
(\%)\end{array}$ \\
\hline Brown et al.. & Rural & Comilla & $\begin{array}{l}\text { Hospital \& } \\
\text { community }\end{array}$ & n.a. & $1-6$ years & 95 & 0.49 & 20 & n.a. & n.a. \\
\hline Molla et $a .^{28}$ & Urban & Dhaka & Hospital & n.a. & $3-9$ years & 13 & 0.80 & n.a. & n.a. & n.a. \\
\hline Stoll et al. ${ }^{27}$ & Urban & Dhaka & Hospital & n.a. & $1-10$ years & 30 & n.a. & 66 & 100 & - \\
\hline Henning et $a l^{29}$ & Rural \& urban & $\begin{array}{c}\text { Comilla \& } \\
\text { Dhaka }\end{array}$ & Hospital & 1987 & $1-5$ years & 36 & $\begin{array}{l}0.76^{\star} \\
0.88^{\star \star}\end{array}$ & n.a. & n.a. & n.a. \\
\hline Rahman et al. ${ }^{30}$ & Urban & Dhaka & Hospital & n.a. & $6-17$ weeks & 183 & $\begin{array}{l}0.43^{*} \\
0.47^{*}\end{array}$ & 35 & 87 & 100 \\
\hline Wahid et al.. & Urban & Dhaka & Hospital & 1994 & 2-11 months & 85 & 0.66 & 18 & 56 & n.a. \\
\hline
\end{tabular}

Values at baseline: *treatment group; ${ }^{* *}$ control group; n.a., not available. 
adolescent girls aged $12-15$ years had serum retinol levels less than $1.05 \mu \mathrm{moll}^{-1}$. Adolescent females working in garment factories in Dhaka city ${ }^{36}, 56 \%$ had serum retinol levels less than $1.05 \mu \mathrm{moll}^{-1}$, and $14 \%$ had levels less than $0.70 \mu \mathrm{mol}^{-1}$, indicating a significant public health problem. In a study of 563 adolescent school girls in periurban areas of Dhaka district ${ }^{37}, 39 \%$ had serum retinol levels below $1.05 \mu \mathrm{moll}^{-1}$, with $3 \%$ having levels less than $0.70 \mu \mathrm{moll}^{-1}$.

The last nutrition survey in 1981-82 indicated that the average intake of vitamin A amongst children aged 7-9 years was 68\% of the RDA ${ }^{17}$, based on WHO 1974. In adolescents (10-19 years) average vitamin A intake was even lower; ranging from 20 to $58 \%$ of the $\mathrm{RDA}^{17}$. Hassan and Barua ${ }^{38}$ found that the average vitamin A intake of 82 male children aged 5-15 years in an orphanage in Dhaka city was $97 \%$ of RDA. In one study of 76 adolescent females working in garment factories in Dhaka city, the mean intake of vitamin A was reported to be lower than the $\mathrm{RDA}^{39}$, in another the mean intake of 63 adolescent garment factory workers was about $49 \%$ of the RDA, and $81 \%$ did not meet the $\mathrm{RDA}^{40}$. For 152 adolescent girls, aged $13-17$ years and attending high school in Dhaka city, the mean vitamin A intake was well above the $\mathrm{RDA}^{41}$. Furthermore, in a representative sample of 385 adolescent girls, aged 10-16 years, from ten high schools in Dhaka city, although the mean vitamin $\mathrm{A}$ intake was $960 \mu \mathrm{g} \mathrm{day}^{-1}$, as many as $62 \%$ of the girls had intakes of vitamin $\mathrm{A}$ which were below the RDA, using Indian standards ${ }^{42}$. The apparent difference in the intake of vitamin A between the two studies may reflect true variability but is perhaps more likely to reflect differences in the design of the studies ${ }^{41,42}$.

In conclusion, the magnitude of clinically evident vitamin A deficiency among school-age and adolescent children has decreased slightly over the past two decades, but remains a significant problem. Furthermore, the situation appears to be worse in males than in females. The measurement of serum retinol levels indicates the extent of subclinical vitamin A deficiency among these age groups. For the working adolescent girls living in urban slums the situation is appalling. The data on dietary vitamin A intake serve to confirm that vitamin A deficiency among adolescent girls remains a substantial and important public health problem.

\section{Adult males}

The nutrition survey in 1981-82 revealed that $9.6 \%$ of the adult males in rural Bangladesh had conjunctival xerosis and $0.5 \%$ had night blindness ${ }^{17}$. Khan et al. ${ }^{20}$ found that the prevalence of xerophthalmia in adult males was $0.34 / 1000$. Saha et al. ${ }^{22}$ reported that $2.9 \%$ of 70 males had night blindness in rural areas with no safe water supply; while there were none in the areas with safe water supply, indicating that poor hygiene is related to the severity of the vitamin A deficiency. In the 1981-82 survey, the average vitamin A intake of adult males was found to be low, ranging from 32 to $57 \%$ of the $\mathrm{RDA}^{17}$. Recently, we have found that in 252 rickshaw pullers, the largest group of manual workers in Dhaka city, $71 \%$ had intakes of vitamin A below the $\mathrm{RDA}^{43}$.

To conclude, based upon the limited data, for adult

Table 5 Summary of the data on the prevalence of serum retinol levels suggestive of a public health problem in different demographic population groups of Bangladesh

\begin{tabular}{|c|c|c|c|c|c|c|c|c|c|c|c|}
\hline \multirow[b]{2}{*}{ Reference } & \multirow[b]{2}{*}{$\begin{array}{l}\text { Study } \\
\text { population }\end{array}$} & \multirow[b]{2}{*}{ Area } & \multirow[b]{2}{*}{ Place } & \multirow[b]{2}{*}{ Setting } & \multirow[b]{2}{*}{$\begin{array}{l}\text { Study } \\
\text { period }\end{array}$} & \multirow{2}{*}{$\begin{array}{c}\text { Age } \\
\text { group } \\
\text { (years) }\end{array}$} & \multirow[b]{2}{*}{$\begin{array}{l}\text { Sample } \\
\text { size }\end{array}$} & \multirow{2}{*}{$\begin{array}{c}\text { Mean } \\
\text { serum } \\
\text { retinol } \\
\left(\mu \mathrm{moll}^{-1}\right)\end{array}$} & \multicolumn{3}{|c|}{$\begin{array}{l}\text { Serum retinol level } \\
\qquad\left(\mu \mathrm{moll}^{-1}\right)\end{array}$} \\
\hline & & & & & & & & & $\begin{array}{c}<0.35 \\
(\%)\end{array}$ & $\begin{array}{c}<0.70 \\
(\%)\end{array}$ & $\begin{array}{c}<1.05 \\
(\%)\end{array}$ \\
\hline Ahmed et al. ${ }^{34}$ & $\begin{array}{l}\text { School-age } \\
\text { children }\end{array}$ & Urban & Dhaka & School & n.a. & $5-12$ & 242 & $>1.05$ & - & 4 & 20 \\
\hline Ahmed et al. ${ }^{35}$ & $\begin{array}{l}\text { Adolescent } \\
\text { girls }\end{array}$ & Urban & Dhaka & School & 1992 & $12-15$ & 225 & $>1.05$ & - & - & 11 \\
\hline Ahmed et al. ${ }^{36}$ & $\begin{array}{l}\text { Adolescent } \\
\text { female } \\
\text { workers }\end{array}$ & Urban & Dhaka & Factory & 1996 & $12-19$ & 388 & 1.04 & 0.5 & 14 & 56 \\
\hline Ahmed et al. ${ }^{37}$ & $\begin{array}{l}\text { Adolescent } \\
\text { girls }\end{array}$ & Periurban & Dhaka & School & 1996 & $10-17$ & 563 & 1.15 & - & 3 & 39 \\
\hline Nahar et al. ${ }^{44}$ & $\begin{array}{l}\text { Female } \\
\text { workers }\end{array}$ & Urban & Dhaka & Factory & n.a. & $20-35$ & 63 & 1.19 & 9 & 56 & n.a. \\
\hline Barua and Begum ${ }^{47}$ & $\begin{array}{l}\text { Women at } \\
\text { delivery }\end{array}$ & Urban & Dhaka & Hospital & n.a. & $15-40$ & 85 & n.a. & - & 5 & 30 \\
\hline Hasin et al. ${ }^{48}$ & $\begin{array}{l}\text { Women at } \\
\text { delivery }\end{array}$ & Urban & Dhaka & Hospital & 1994 & $20-30$ & 151 & 1.33 & - & - & 30 \\
\hline Roy et al. ${ }^{50}$ & $\begin{array}{l}\text { Women at } \\
\text { delivery }\end{array}$ & Urban & Dhaka & Hospital & n.a. & $16-35$ & 50 & $>1.05$ & n.a. & n.a. & n.a. \\
\hline
\end{tabular}

n.a., Not available. 
males in Bangladesh, the intake of vitamin A and vitamin A status is generally poor and a cause for concern, although there is a lack of recent information.

\section{Adult females}

The nutrition survey of 1981-82 showed that the prevalence of conjunctival xerosis among nonpregnant and non-lactating (NPNL) women in rural Bangladesh was 2.6\%; none were found to have night blindness ${ }^{17}$. Khan et al. $^{20}$ showed that the rate of xerophthalmia was $0.1 / 1000$ in adult females. Saha et $a l^{22}$ found that the prevalence of night blindness among NPNL women was higher in the area with no safe water supply, $1.39 \%$, than in the area with safe water supply, $0.65 \%$.

In only one study has the biochemical assessment of vitamin A status been made in NPNL females (see Table 5). In 63 females working in the garment factories in Dhaka city ${ }^{44}, 9 \%$ had serum retinol level below $10 \mu \mathrm{mol} \mathrm{l}^{-1}$, with $56 \%$ having levels $\leq 0.70 \mu \mathrm{mol} \mathrm{l}^{-1}$.

In the survey of 1981-82, average vitamin A intake of NPNL women ranged from 26 to $47 \%$ of $\mathrm{RDA}^{17}$. A recent study in 7341 women of reproductive age who participated in a home gardening project in rural Bangladesh found that the mean daily intake of vitamin A was 511 retinol equivalents and the median intake was 400 retinol equivalents ${ }^{45}$, indicating a substantial increase in vitamin $\mathrm{A}$ intake by the rural women compared to the results of the national survey of 1981-82. Sultana et al. ${ }^{46}$ showed that mean vitamin A intakes for 60 students resident in Dhaka University was 39\% of the RDA, and for 51 garment factory workers was 19\% of the $\mathrm{RDA}$, indicating a poor vitamin A intake of urban adult females. Two other studies of females working in garment factories in Dhaka city showed that the average intakes of vitamin A was $73 \%{ }^{40}$ and $82 \%{ }^{39}$ of the RDA.

In summary, over the years some progress has been made in improving the situation and reducing vitamin A deficiency among NPNL women. However, more focused studies are needed to examine the current situation in detail.

\section{Pregnant and lactating women}

The survey of 1981-82 revealed that the prevalence of conjunctival xerosis among pregnant, lactating or pregnant and lactating women in the rural population was $1.6 \%$ and none were found with night blindness ${ }^{17}$. Saha et $a l^{22}$ found that the prevalence of night blindness among pregnant or pregnant and lactating women in areas with a safe water supply was $1.05 \%$ and in areas with no safe water supply, it was $2.44 \%$. The recent report of the Nutritional Surveillance Project of the HKI has shown that the rate of night blindness among rural mothers is as high as $1.4 \% 0^{25}$. Thus, there does not appear to have been any decrease in the extent of the vitamin A deficiency in comparison with that reported in the earlier studies.

Biochemical evidence for vitamin A deficiency among pregnant women is limited and mainly derived from hospital-based studies (see Table 5). Barua and Begum $^{47}$ showed that $5 \%$ of 85 women had serum retinol levels less than $0.70 \mu \mathrm{mol}^{-1}$ at delivery, and for $25 \%$ the values were between 0.70 and $1.05 \mu \mathrm{moll}^{-1}$. In 151 pregnant women we found that $33 \%$ had serum retinol levels below $1.05 \mu \mathrm{moll}^{-1}$ at delivery ${ }^{48}$. In a study designed to assess the quality of breast milk, 61 mothers of poor socioeconomic status group had low retinol levels ${ }^{49}$. In 50 women from a periurban village near Dhaka city, following vitamin A supplementation the concentrations of retinol in breast milk increased significantly in the $24 \mathrm{~h}$ following supplementation ${ }^{50}$.

The survey of 1981-82 revealed that average vitamin A intake by the pregnant women was $81 \%$ of the RDA, by lactating women was $28 \%$ of the RDA and by pregnant and lactating women was $19 \%$ of the $\mathrm{RDA}^{17}$. Sultana et $_{\text {al }}{ }^{46}$ reported poor intakes of vitamin A (16-26\% of the RDA) by pregnant women of poor socioeconomic group attending a local maternity hospital in Dhaka city.

To summarize, the data on clinical examination and dietary information clearly indicate that the situation of vitamin A deficiency in pregnant and lactating women has not improved over the years and the present magnitude of the problem is a public health concern.

\section{Summary of the situation analysis}

The overall analysis and assessment of the situation in relation to vitamin A deficiency among the different population groups leads to the conclusion that the magnitude of the severe vitamin A deficiency in preschool children has decreased significantly over the past two decades. This success can be attributed largely to the high coverage of the national VAC distribution programme. The magnitude of severe vitamin A deficiency among school-age and adolescent children has also decreased over the past two decades. However, the decrease is less marked and deficiency in this group is still a considerable problem. It is difficult to assess any trend in vitamin A deficiency among NPNL women, but the data from clinical examination and the dietary information suggest that the situation of vitamin A deficiency in pregnant and lactating women has not improved over the years. Similarly, in adult males in Bangladesh, the prevalence of vitamin A deficiency is at a level which is high enough to cause considerable concern, even though the limited information makes it impossible to evaluate trends.

There is substantial biochemical evidence that 
subclinical vitamin A deficiency is now a significant public health problem in preschool children, schoolage children and adolescent population groups. Furthermore, the data on dietary vitamin A intake confirms that overall the intake of dietary vitamin A is inadequate giving rise to the serious situation of widespread deficiency which has not shown sufficient improvement over the past 20 years.

\section{Current programmes for prevention and control of vitamin A deficiency}

This section of the article focuses on the nature and progress of the present policies and programmes which have been developed to impact upon the problem of vitamin A deficiency. This is followed by an evaluation of the extent to which they have been able to achieve their objectives, and any constraints which can be identified in the attempts to control vitamin A deficiency in Bangladesh. In order to control vitamin A deficiency, in 1973 the government of Bangladesh initiated the National Blindness Prevention Programme through the IPHN with assistance from UNICEF. The main activities of the programme included four elements: VAC distribution to the target population twice a year; provision of nutrition education to increase the production and consumption of vitamin A rich foods; training of primary health-care workers in the clinical diagnosis and treatment of vitamin $\mathrm{A}$ deficiency; and nutrition education.

\section{Vitamin A capsule supplementation programme}

In 1973, as a short-term measure, the government of Bangladesh started the distribution of VAC containing 200,000 IU of vitamin A to all children aged 12-71 months and 100,000 IU of vitamin A to children under 12 months, through the National Blindness Prevention Programme. The programme has been conducted twice a year through door-to-door domiciliary visits by field level health workers: one visit in April-May and the other in October-November. The distribution of VAC in rural areas was carried out by the Family Welfare Assistant and Health Assistant, and the municipal and non-government organization (NGO) workers covered urban areas. The programme has had difficulty in achieving high coverage rates continuously throughout the country. The VAC distribution coverage rate in rural areas has been stagnant at a low level: $45 \%$ (a range of 16-85\%) in $1982-83^{51} ; 37 \%$ in 1987-88; and $35 \%$ in $1989^{19}$.

In the mid-1990s, the vitamin A supplementation programme to children under 12 months of age was integrated into the outreach clinics of the Expanded Programme on Immunization (EPI), which resulted in an increase in coverage for the distribution of vitamin A among the young children. Children were given a total of three doses of 50,000 IU each: one at 6 weeks, one at 10-14 weeks and, finally, one at 36 weeks of age. A single dose of vitamin A supplementation for infants at EPI outreach clinics has now been changed to $25,000 \mathrm{IU}$. The first dose is given at 6 weeks of age. Since 1994, liquid vitamin A has been administered to children under 12 months using a dose dispenser (25,000 IU). For children aged 12-71 months, the VAC distribution policy has remained the same, i.e. a dose of 200,000 IU every 6 months given during a home visit. From June 1990 to April 1994, VAC coverage rate was fairly steady, between 42 and 55\% among children 6-59 months. VAC distribution dropped to $31 \%$ in August 1994 because of the cessation of funding by the Swedish Government to UNICEF for VAC procurement ${ }^{51}$. Subsequently, the World Bank provided funds and in October 1994, the coverage rate had risen once more to $45 \%$.

In 1995, to improve the coverage of VAC distribution, vitamin A administration for 1-6-year-old children was integrated with the National Immunization Day (NID). One-day VAC distribution initiative took place in April 1995 in conjunction with the second NID. This arrangement was highly successful. The result of this initiative was reflected in the routine data collection of the Nutritional Surveillance Project of HKI in June 1995. The coverage rate of VAC distribution was as high as $87 \%$ in rural Bangladesh ${ }^{25}$.

Following the success of VAC distribution during the NID, the government of Bangladesh planned a week-long nationwide mobilization campaign: 'National Vitamin A Week', organized by the IPHN, in which VAC were distributed through outreach centres. The Nutritional Surveillance Project report in December 1995 indicated the coverage of VAC distribution was $83.6 \%$ in rural areas and $73.7 \%$ in urban $\operatorname{areas}^{25}$. Thus, the strategy of using a high impact short duration approach was very successful once more. Encouraged by these experiences, the government of Bangladesh adopted a VAC distribution strategy for children $12-71$ months in both NID and National Vitamin A Week. A recent evaluation of the universal distribution of vitamin A capsules programme showed that vitamin A supplementation is an effective strategy for reducing vitamin A deficiency ${ }^{52}$.

Given the problems associated with vitamin A deficiency amongst women and the implications this has for the health of the mother during pregnancy and lactation, and the further effect on the health and survival of newborns and infants, the government of Bangladesh has decided recently to supplement mothers within 14 days of delivery with VAC (200,000 IU). However, so far no effective measures have been formulated for VAC distribution to postpartum mothers. The mega-dose capsules (200,000 IU) 
were included in 'safe delivery kits' that have been made available by some NGOs and sold for clean deliveries, and to be used by the traditional birth attendants. Currently, UNICEF is supporting studies with the objective of identifying more effective strategies for vitamin A supplementation of mothers within 2-4 weeks postpartum period. More recently, IPHN took an initiative in implementing VAC supplementation to lactating mothers and children suffering with diarrhoea, measles and pneumonia. The Bangladesh Integrated Nutrition Project has also started VAC distribution to mothers within 14 days after delivery and early results indicate a high (57\%) postpartum VAC coverage ${ }^{53}$.

According to Greiner ${ }^{54}$ the cost of VAC distribution is estimated to be about US\$0.05 dose recipient ${ }^{-1}$ year $^{-1}$. These estimates are marginal costs as they do not include any of the actual costs involved for the government or NGO health programmes, nor the periodic costs for national surveys. The report also estimated the cost-effectiveness of the programme: with a nationwide VAC coverage rate of $40-50 \%$, night blindness would be reduced by $20-25 \%$ and mortality would be decreased by $30-40 \%$ with $100 \%$ coverage $^{54}$. In a recent assessment by the World Bank, the number of productive years gained per dollar invested for vitamin A supplementation ranked highest in the order when compared with other recognized approaches or technologies designed to reduce mortality ${ }^{55}$.

Despite the welcome recent successes in VAC distribution and coverage, the programme in Bangladesh is fragile. The programme is entirely dependent on foreign aid resources and evidence of its fragility is provided by the breakdown in coverage rate when there was a change from one donor source to another in 1994. Although the programme has achieved a smooth routine after so many years, and community participation and political support seemed to have increased, still there remains the question of financial sustainability of the VAC distribution programme.

\section{Home gardening}

Home gardening is a traditional system for family food production which is widely practised in south Asia. A programme based upon home gardening has been introduced which has as its goal a reduction in vitamin A deficiency and an improvement in household food security. This is to be achieved by promoting the production and consumption of vitamin A rich fruits and vegetables by poor households, which at the same time can effectively increase household income. In 1988, the HKI undertook the first pilot project on home gardening in north Bengal. By 1992, about 13 nongovernment and two government organizations were involved in home gardening ${ }^{56}$. However, for only two non-government organizations did the implementation of home garden activities carry a specific focus on vitamin A. Home gardening activities have expanded since 1992 and at present about 60-70\% thanas (subdistricts) have some form of home gardening activities. The Agricultural Support Services Programme of the government has played an important role in coordinating activities which relate to and facilitate the development of successful home gardening, which includes the promotion of a vegetable seed industry.

The success of the home gardening programme in Bangladesh has benefited from financial support from a range of international agencies, such as the United States Agency for International Development, the Netherlands Organization for International Development Cooperation, the Australian High Commission in Bangladesh and the Overseas Development Administration of the UK. Most recently, the Department of Agricultural Extension of the Ministry of Agriculture also added their support to the home gardening programme.

A recent report by Bloem et al..$^{45}$ showed that the vitamin A intake of the population in areas where home gardening is practised was derived almost entirely from the consumption of fruits and vegetables. The health implications of this were explored statistically, using logistic regression analyses, and it was shown that the vitamin A intake of mothers was determined by qualitative indicators of homestead gardens even when account was taken of their overall socioeconomic status ${ }^{45}$. Earlier studies by the HKI have suggested that income from home gardens could provide about $15 \%$ of energy requirement for each household member. Home gardening is likely to help all the members of the household, while the biannual distribution of high-dose vitamin A capsules will only target children aged less than 60 months. Thus, without special attention vitamin A deficient adults, especially women, remain at high risk for vitamin A deficiency and the inevitable health consequences. Home gardening can increase the availability of vitamin A within the household and potentially this can be achieved without the need for a continuous supply of VAC from external sources. On this basis, therefore, a strategy in which a central element is the objective of supplying enough vitamin A through approaches such as the use of home gardening has a much greater potential for sustainability and wider social coverage than periodic capsule distribution ${ }^{45}$. The HKI and Worldview International Foundation (WIF) implemented a Nutritional Blindness Prevention Programme in Gaibanda district based on health education and home gardening concepts. The evaluation of the project reported an increase of $40-60 \%$ in the production and consumption of green leafy vegetables and yellow fruits by children. The prevalence of night blindness dropped and the programme $\operatorname{cost}^{54}$ was only US $\$ 0.11$ target group 
recipient $^{-1}$ year $^{-1}$. Furthermore, the report also indicated that the home gardening programme is likely to be a more sustainable approach than a VAC distribution programme. It involves more community participation, reaches the poor better and provides more benefits for women ${ }^{54}$.

Although, at the current level of operation the home gardening programme has been a successful project in Bangladesh in terms of production and consumption of vegetables ${ }^{56}$, there are difficulties in going for scale and sustainability which persist. These may be expected to reduce as experience grows as by and large they appear to relate to issues such as inadequate counselling in nutrition, the provision of unsuitable dietary advice which is not based on appropriate information, education and communication initiatives.

\section{Fortification}

As yet in Bangladesh, there have not been any effective measures which have sought to address the problem of vitamin A deficiency through the fortification of foods. One of the major underlying problems has been the need to identify a suitable vehicle which can be fortified with vitamin $\mathrm{A}$ and is available to most of the population at risk. However, a study by the Assistance for Blind Children assessed the feasibility of using oil and sugar as possible vehicles for vitamin A fortification. The report indicated that the consumption of oil and sugar were 8 and $5 \mathrm{~g} \mathrm{day}{ }^{-1}$, respectively and fairly consistent across all economic groups ${ }^{57}$. The study also showed that all locally produced sugar is manufactured by sugar mills under the Bangladesh Sugar and Food Industries Corporation, and therefore it would be possible to exert central control over any fortification. The refining of edible oil is dispersed among 17 units in Bangladesh. Recently, UNICEF has assessed the feasibility of vitamin A fortification, and invited owners of the vegetable oil mill and the wheat flour mill, to explore the possibility of developing the fortification of food with vitamin A.

\section{Recommendations for action}

In 1990, the World Summit for Children adopted a declaration which as a global objective called for the virtual elimination of vitamin A deficiency and its consequences by the year 2000. In 1992, at the International Congress of Nutrition, this goal was restated. There has been a quantum increase in terms of the awareness of the problem and the adoption of actions which will in time ensure its elimination. However, this review of the present situation of trends in the prevalence of vitamin A deficiency make it clear that although the rates of clinical deficiency have dropped significantly over the past two decades, over the same period the rates of subclinical deficiency have shown an increasing trend. Thus, even if a substantial impact on the grossest manifestations of vitamin A deficiency has been achieved by the year 2000, any complacency that the problem has been resolved should be sternly resisted. New goals will need to take into account the potential devastating impact that milder forms of deficiency carry, and may need to be stated in more modest terms, at least for Bangladesh.

There are clearly political attractions in setting a single dramatic challenge which might be addressed by a single simple approach. The reality is more subtle and a greater challenge. It is important to appreciate that no single intervention strategy is likely to be entirely successful, under all circumstances. High impact approaches which operate over the short term are of importance and have their place. Nevertheless, the most fundamental strategy to achieve the goal should be aimed at long-term approaches with a focus on prevention and control. There is the need to find the most suitable combination of long-term sustainable action with short-term measures for immediate action. Thus acceleration of sustainable progress towards elimination of vitamin A deficiency will require an appropriate mix of interventions which are integrated into a development context that reflects human well-being as well as national priorities. In Bangladesh, the focus of the major thrust so far has been to provide supplements to young children. Other interventions, such as the promotion of consumption of foods rich in vitamin A are also gaining ground and have the potential to be more sustainable in the longer term. However, the impact of these measures has been uneven owing to problems in the adequate implementation of programmes. Based upon the assessment and analysis of the problem and existing intervention strategies for controlling vitamin A deficiency presented in the preceding sections, it is possible to be optimistic and make a series of recommendations which have a reasonable chance of ensuring the complete eradication of vitamin A deficiency and it consequences by the year 2010 (Table 6).

\section{Continuation of VAC supplementation}

In Bangladesh, VAC supplementation is reported to be a successful programme in reducing the prevalence of night blindness in preschool children ${ }^{52}$. Given that the dietary intake of vitamin A is unlikely to show marked improvement in the near future, VAC supplementation should continue as a short-term strategy for the prevention of vitamin A deficiency. Currently there seems to be no viable alternative to the VAC distribution programme. Thus, VAC distribution should be continued until long-term, sustainable approaches can be 
introduced. Since recent studies have indicated that vitamin A deficiency exists among women of reproductive age, vitamin A supplementation with VAC to postpartum mothers should be an effective immediate measure to improve the vitamin A status of the lactating mothers as well as breast-fed infants. Therefore, in addition to preschool children, clear guidelines for postpartum VAC distribution is necessary and health workers must receive appropriate training in their implementation.

The vitamin A status of pregnant women not only determines the vitamin A status of the newborn, but also, to a great extent, influences the vitamin A status of the infants. Hence, ensuring adequate vitamin A intake during pregnancy would be a more rational approach to improve the vitamin A status of both mother and offspring. Supplementation of pregnant women has not been advised in the past due to possible side-effects on the fetus. The perspective on this recommendation is, however, changing provided that it is possible to ensure safety through the effective distribution of a low-dose capsule (5000-10,000 IUday ${ }^{-1}$ ). Since the prevalence of night blindness is quite high among women of reproductive age in Bangladesh, a targeted low-dose vitamin A supplementation programme for women of reproductive age is also deemed necessary.

The 'National Vitamin A Week', as a centre-based approach, proved to be very effective. Nevertheless, it was not perfect in all respects and there is room for improvement. Perhaps use of mass media and special communication programme should be important components of the programme. Special attention needs to be drawn to areas with low coverage to improve their distribution performance.

To continue the VAC supplementation programme, it is important to have a continuous source of funding. At present the VAC supplementation programme is totally dependent on foreign donor agencies and continued dependence on donated funds may endanger the programme in the near future. A national fundraising campaign to obtain local funding will be the best option to secure continuation of the current VAC distribution programme.

\section{Expansion of home gardening activity}

Recognizing that the VAC distribution programme in Bangladesh should be a short-term approach and appreciating its limitations, it is time to focus on longterm sustainable programmes. The long-term strategy to alleviate vitamin A deficiency is to improve the dietary intake of vitamin A. This can be achieved by increasing the availability of vitamin A rich foods at household level. Home gardening is a successful intervention programme in Bangladesh, which has increased the availability of vitamin A rich foods as well as economic benefits to the poor rural households. Thus, home gardening activities should be expanded throughout Bangladesh. A nationwide campaign is necessary to encourage production and consumption of vitamin A rich vegetables and fruits. This can be achieved through NGOs, schools and health centres. Additionally, community leaders and volunteers should be involved in the promotion of gardening at the household level.

\section{Introduction of food fortification}

Potentially, one of the most effective ways to improve the vitamin A status of the entire population and every group at risk is through the fortification of food with vitamin A. As a medium-term strategy it holds considerable possibilities for the alleviation of vitamin A deficiency in Bangladesh. However, there are a number of technical issues which have to be addressed. There is the need to select an appropriate vehicle for vitamin A fortification, and this has to be consumed in appropriate amounts by all members of the target communities. Furthermore, there will be the need to promote changes in dietary behaviour which will ensure that there is adequate consumption of the vehicle. Given the magnitude and severity of the problem of vitamin A deficiency, a pilot project to fortify at least one or two suitable food items with vitamin A needs to be initiated. It may be advisable to target the pilot study to the most vulnerable groups in the first instance, without trying to cover the entire population.

\section{Promotion of dietary diversification}

Dietary modifications have long been recognized,

Table 6 Key recommendations for action to improve the present situation of vitamin A deficiency in Bangladesh

\begin{tabular}{ll}
\hline Measure & \multicolumn{1}{c}{ Intervention programmes } \\
\hline Short term & $\begin{array}{c}\text { Continuation of vitamin A capsule supplementation } \\
\text { children under } 6 \text { years } \\
\text { postpartum mothers } \\
\text { Introduction of food fortification with vitamin A }\end{array}$ \\
Ledium term & $\begin{array}{l}\text { Expansion of home gardening activity } \\
\text { Promotion of dietary diversification } \\
\text { Promotion of breastfeeding } \\
\text { Strengthening nutrition education }\end{array}$ \\
\hline
\end{tabular}


and recently re-emphasized as the safest and most sustainable long-term measure to control vitamin A deficiency in a population at risk. Since an approach based upon home gardening alone may not be sufficient in alleviating vitamin A deficiency, additional strategies need to be considered: such as the introduction of poultry, small animal husbandry or fish cultivation in local ponds. Consumption of foods which can be produced through these strategies: eggs, milk and whole fish will provide vitamin A in the diet which has high bioavailability.

\section{Promotion of breastfeeding}

Breastfeeding is essentially the only source of vitamin A for the first few months in infants and often continues to be the most important source up to 2 years of age. Exclusive breast feeding for 4-6 months and continued breastfeeding with complimentary foods thereafter should be promoted to improve the vitamin A status of the infants.

\section{Strengtbening nutrition education}

It has been well documented that nutrition education is an essential element in any strategy to reduce vitamin A deficiency. In Bangladesh, the WIF with the support from donors in Norway, Holland and Sweden, launched a programme to reduce vitamin A deficiency using the mass media and interpersonal communication to encourage home and school gardening. The WIF programme has covered five districts with a total population of 5 million. A recent report in which the programme was evaluated showed that after 3 years of implementation, production of green leafy vegetables in household garden had substantially increased ${ }^{58}$. The report also indicated an increased consumption of green leafy vegetables by young children. The prevalence of night blindness was reduced to approximately half the level reported in the baseline survey ${ }^{58}$. Thus, nutrition education seems to be an important medium-term measure for improving vitamin A status in the community and especially of vulnerable groups. Steps should be taken to strengthen the nutrition education programme to increase knowledge as well as attitudes and practices concerning the consumption of vitamin A rich foods. A nutrition education programme can be carried out through schools and health centres. This should be coupled with social marketing of vitamin A rich foods using a variety of means including mass communication.

\section{Recommendations for research and evaluation}

\section{Evaluation of current vitamin A status}

A national survey is needed to estimate the current prevalence of vitamin A deficiency in Bangladesh in order to evaluate the programme input. In late 1997, the HKI in collaboration with IPHN and INFS, conducted a national survey on vitamin A deficiency with the financial support from UNICEF. This survey was designed to estimate the current prevalence of night blindness and also by measuring serum retinol levels to assess the frequency of subclinical vitamin A deficiency. It is expected that the findings of the survey will be ready for distribution in late 1998 .

\section{Evaluation of the impact of bome gardening}

The HKI and WIF implemented a Nutritional Blindness Prevention Programme in Gaibanda district based on health education and home gardening concepts. For the purpose of the evaluation, the project design incorporated pre- and postintervention surveys to examine the impact on the households. However, evaluation of the project did not directly test for any changes in the prevalence of vitamin A deficiency among the population. Rather, the project used indirect indicators to measure impact, including consumption of vegetables by children and prevalence of night blindness ${ }^{58}$. Thus, it will be important to evaluate the impact of the home gardening programme in reducing vitamin A deficiency using more direct indicators, such as serum retinol levels. With support from USAID, an evaluation of the HKI home gardening activities is being conducted by the International Centre for Diarrhoeal Disease Research, Bangladesh (ICDDR, B).

\section{Operational research}

The best current long-term strategy is extension of homestead gardening for increased vegetable production and consumption, but this single intervention will not provide a comprehensive solution. Thus continued research is necessary to search for alternative and improved interventions. Operations research should also address appropriate strategies for VAC administration to women of reproductive age.

It is now crucial to identify a suitable vehicle that can be used for vitamin A fortification, and can be largely consumed in a majority of the population and in similar amounts by most of the community members. Furthermore, the vehicle should be the item which can be centrally controlled for vitamin A fortification. Operations research should be carried out to identify such a vehicle.

Finally, in order to achieve the goal action is needed at every level and within many sectors. Government officials must incorporate the goal of virtual elimination of vitamin A deficiency and its consequences in the national policies, and they must ensure that the needed resources are allocated and made available to ensure that programmes benefit from proper management and accountability. International organizations must help with advocacy, general guidelines and technical assistance in addition to programme support. NGOs 
should help with programme implementation and advocacy. Private industry should be involved in the product development and manufacture of food, and ensure the delivery and quality assurance of their products. At the community level, there is a need to inform every person about the serious consequences of vitamin A deficiency, while providing hope that their own efforts can make a substantial contribution to solving the problem, thereby harnessing their creative abilities and ensuring full community participation. There is a persistent need to ensure that effort is maintained and appropriate steps continued for improving the condition, through the full involvement of researchers and health professionals.

\section{Conclusion}

This article has attempted to review the present situation in relation to vitamin A deficiency in Bangladesh. It has included information on the existing intervention strategies and specific needs and key options for action to improve the situation. Over the past few decades a good number of studies including national nutrition surveys have been carried out to investigate the prevalence of vitamin A deficiency among different population groups in Bangladesh, and demonstrated a significant public health problem. The magnitude of the problem is considerable, especially among preschool children, adolescents and women of reproductive age. Although the prevalence of night blindness in preschool children has decreased over the past two decades, the biochemical assessment of vitamin A status based upon the measurement of serum retinol levels reveal that there is a high prevalence of subclinical vitamin A deficiency. Among school-age children and adolescents, the prevalence of night blindness and Bitot's spot has decreased slightly over the same period of time, however, it is still a significant problem. Furthermore, recent reports indicate that night blindness among rural mothers is as high as $1.4 \%$. Only a limited number of studies, with a small sample size, provide information on serum retinol levels in school-age children, adolescents and pregnant women. Nevertheless, these studies confirm low serum retinol levels, indicating the risk of subclinical vitamin A deficiency. Furthermore, the dietary intake of each population group was found to be less than the RDA, denoting dietary problems as a significant risk factor for vitamin A deficiency.

Several strategies have been developed with the objective of controlling vitamin A deficiency in Bangladesh. The biannual distribution of high-dose vitamin A capsules to children under 60 months of age was found to be effective in reducing deficiency. However, this programme is only beneficial for preschool children. Other programmes like home gardening and nutrition education including social marketing have been in operation for a long time, however, each of the programmes has its limitation. Although some progress has been made in improving the situation, the magnitude of the problem makes it clear that there is a need for more sustainable long-term approaches to alleviate the problem of vitamin A deficiency for the entire population. To achieve the goal of virtual elimination of vitamin A deficiency will require integrated approaches and the action is needed at every level and also within many sectors.

\section{Acknowledgements}

I gratefully acknowledge Dr TO Kyan-Myint, UNICEF, Dhaka, and Professor Alan A Jackson, Institute of Human Nutrition, Southampton for their valuable suggestions and constructive criticisms on the manuscript.

\section{References}

1 McLaren DS, Frigg M. Sight and Life Manual on Vitamin A Deficiency Disorders (VADD). Basel, Switzerland: Task Force Sight and Life, 1997.

2 Blomhoff R, Green MH, Norum KR. Vitamin A metabolism: new perspectives on absorption, transport, and storage. Physiol. Rev. 1991; 71: 951-90.

3 Sommer A, West KP Jr. Vitamin A Deficiency: Health, Survival and Vision. New York: Oxford University Press, 1996.

4 WHO Expert Group. Vitamin A Deficiency and Xerophthalmia. Tech. Rep. Ser. No. 590. Geneva: WHO, 1982.

5 WHO. Indicators for Assessing Vitamin A Deficiency and their Application in Monitoring and Evaluating Intervention Programmes. Geneva: WHO, 1996.

6 WHO. Global Prevalence of Vitamin A Deficiency. WHO, Micronutrient Deficiency Information System (MDIS) Working Paper No. 2. WHO/UNICEF. Doc. WHO/NUT/95. 3. Geneva: WHO, 1995.

7 Udomkesmalee E. Vitamin A deficiency in Asia. Vital News 1992; 3(3): 1-5.

8 Upadhyay MP, Gurung BJ, Pillai KK, Nepal BP. Xerophthalmia among Nepalese Children. Am. J. Epidemiol. 1985; 121: 71-7.

9 Gopaldas T. Vitamin A deficiency beyond the preschool years. In: West KP Jr, ed. Rapporteur. Bellagio Meeting on Vitamin A Deficiency and Childhood Mortality. New York: Helen Keller International, 1992.

10 Mandal GS, Nanda KN, Bose J. Night blindness in pregnancy. J. Obstet Gynecol. India 1969; 19: 453-8.

11 Katz J, Khatry SK, West KP Jr et al. Night blindness during pregnancy and lactation in rural Nepal. J. Nutr. 1995; 125: 2122-7.

12 UNDP. The Dancing Horizon. Human Development Prospects for Bangladesh. UNDP, 1997.

13 UNICEF. The State of the World's Children 1997. Oxford: Oxford University Press, 1997.

14 US-DHEW. Nutrition Survey of East Pakistan, March 1962January 1964. United States Department of Health, Education and Welfare, Public Health Service, 1966.

15 Kamel WW. Assignment Report on Blindness Prevention Programme, Bangladesh. New Delhi: WHO, 1972.

16 INFS. Nutrition Survey of Rural Bangladesh, 1975-76. Dhaka, Bangladesh; Institute of Nutrition and Food Science, University of Dhaka, 1977.

17 INFS. Nutrition Survey of Rural Bangladesh, 1981-82 Dhaka, Bangladesh: Institute of Nutrition and Food Science, University of Dhaka, 1983. 
18 HKI/IPHN. Bangladesh Nutritional Blindness Study, 198283. Dhaka, Bangladesh: Helen Keller International and Institute of Public Health Nutrition, 1985.

19 IPHN/UNICEF. Nutritional Blindness Prevention Programme Evaluation Report, 1989. Dhaka, Bangladesh: Institute of Public Health Nutrition and UNICEF, 1989.

20 Khan MU, Haque E, Khan MR. Nutritional occular diseases and their association with diarrhoea in Matlab, Bangladesh. Br. J. Nutr. 1984: 52: 1-9.

21 Islam MN, Yusuf HKM. Incidence of nightblindness in preschool children of rural Bangladesh: new risk factors Envisaged. Bangladesh J. Nutr. 1990; 3: 21-7.

22 Saha AR, Ahmed K, Hossain A. Clinical symptoms of micronutrients deficiency in two rural Bangladesh communities with and without the supply of safe drinking water. Bangladesh. J. Nutr. 1991; 4(2): 1-7.

23 Sikder ZU, Henry FJ, Hussain M, Rahman M. Xerophthalmia malnutrition and diarrhoea in urban Bangladesh: a clinic based study. Indian Pediatr. 1988; 25: 946-51.

24 Mahalanabis D. Breast feeding and vitamin A deficiency among children attending a diarrhoea treatment centre in Bangladesh: a case-control study. Br. Med.J. 1991; 303: 493-6.

25 HKI. Nutrition Surveillance Project, Report of Round 41. Dhaka: Helen Keller International, 1996.

26 Brown KH, Rajan MM, Chakraborty J, Aziz KMA. Failure of a large dose of vitamin A to enhance the antibody response to tetanus toxoid in children. Am. J. Clin. Nutr. 1980; 33: 212-17.

27 Stoll BJ, Banu H, Kabir I, Molla A. Nightblindness and vitamin A deficiency in children attending a diarrhoeal disease hospital in Bangladesh. J. Trop. Pediatr. 1985; 31: 36-9.

28 Molla A, Islam A, Molla AM, Jahan F. Change in serum vitamin A concentration after an oral dose in children with acute diarrhoea. J. Pediatr. 1983; 103(6): 1000-2.

29 Henning B, Stewart K, Zaman K, Alam AN, Brown KH, Black RE. Lack of therapeutic efficacy of vitamin A for noncholera, watery diarrhoea in Bangladeshi children. Eur. J. Clin. Nutr. 1992; 46: 437-43.

30 Rahman MM, Mahalanabis D, Wahid MA, Islam MA, Habte D. Administration of $25,000 \mathrm{IU}$ vitamin A doses at routine immunization in young infants. Eur. J. Clin. Nutr. 1995; 49: 439-45.

31 Wahid MA, Alvarez JO, Rahman MM, Hussain M, Jahan F, Habte D. Subclinical vitamin A deficiency in young infants in Bangladesh. Nutr. Res. 1997; 17: 591-8.

32 Brown KH, Black RE, Becker S, Nahar S, Sawyer J. Consumptions of foods and nutrients by weanling in rural Bangladesh. Am. J. Clin. Nutr. 1982; 36: 878-89.

33 Hussain A, Kvale G, Odland M. Diagnosis of night blindness and serum vitamin A level: a population based study. Bull. WHO 1995; 73: 469-76.

34 Ahmed F, Khan MR, Mohiduzzaman M, Shaheen N, Barua S, Bhuyan MAH. Relationship between growth and nutrient status in school children of Urban Bangladesh. In: Said HM, Rahman MA, Abdulla M, Vohora SB, Athar M, eds Elements and Liver: Proceedings of the International Symptoms on Trace Elements and Liver Diseases. Karachi, Pakistan: Hamdard Foundation, pp-26-33, 1996.

35 Ahmed F, Khan MR, Karim R et al. Serum retinol and biochemical measures of iron status in adolescent schoolgirls in urban Bangladesh. Eur. J. Clin. Nutr. 1996; 50: $346-51$.

36 Ahmed F, Hasan N, Kabir Y. Vitamin A deficiency among adolescent female garment factory workers in Bangladesh. Eur. J. Clin. Nutr. 1997; 51: 698-702.

37 Ahmed F, Khan MR, Kabir I, Fuch G. Interrelationship between anthropometric indices, vitamin A and iron status in adolescent girls. Report of the PCC-Collaborative Research Project. Dhaka: ICDDR, B, 1997.

38 Hassan N, Barua S. Nutrition profile of the orphans: a case study in the Dhammarajika Orphanage of Dhaka city. Bangladesh J. Nutr. 1990; 3: 43-53.

39 Sarker BR, Abdullah M, Sarker SK. Dietary intake pattern among Bangladesh female workers in garment factories and their health problem. Bangladesh J. Nutr. 1993; 6: 73-8.

40 Huq SF. Nutritional profile and prevalence of anaemia in female garment workers. M.Sc. thesis. University of Dhaka Dhaka, Bangladesh, 1994.

41 Ali SMK, Islam K, Pramanik MA, Bhuiyan NH, Begum NN Availability of nutrients for adolescent girls. Bangladesh $J$. Nutr. 1994; 7: 13-17.

42 Ahmed F, Zareen M, Khan MR, Banu CP, Haq MN, Jackson AA. Dietary pattern, nutrient intake and growth of adolescent school girls in urban Bangladesh. Publ. Health. Nutr. 1998; 1(2): 83-92.

43 Ahmed F, Khandaker MAI. Dietary pattern and nutritional status of Bangladeshi manual workers (Rickshaw pullers) Int. J. Food Sci. Nutr. 1997; 48: 285-91.

44 Nahar L, Huq SF, Barua S, Islam MS. Vitamin A and iron status amongst female garment workers. Dhaka Univ. J. Biol. Sci. 1995; 4: 119-24.

45 Bloem MW, Huq N, Gorstein J et al. Production of fruits and vegetables at the homestead is an important source of vitamin A among women in rural Bangladesh. Eur. J. Clin. Nutr. 1996; 50 (suppl. 3), S62-7.

46 Sultana S, Nahar B, Quazi S. Dietary intake of micronutrients in normal state and during pregnancy. Bangladesh J. Nutr. 1990; 4(1): 19-25.

47 Barua S, Begum R. Birth weight in relationship with the level of vitamin A and alpha-tocopherol in cord and maternal serum. Bangladesh J. Nutr. 1996; 9: 41-9.

48 Hasin A, Begum R, Khan MR, Ahmed F. Relationship between birth weight and biochemical measures of maternal nutritional status at delivery in Bangladeshi urban poors. Int. J. Food. Sci. Nutr. 1996; 47: 273-9.

49 Barua S, Tarannum S, Nahar S, Mohiduzzaman M. Retinol and alpha-tocopherol content in breast milk of Bangladeshi mothers under low socio-economic status. Int. J. Food. Sci. Nutr. 1997; 48: 13-18.

50 Roy SK, Islam A, Molla A, Akramuzzaman SM, Jahan F, Fuchs G. Impact of a single megadose of vitamin A at delivery on breastmilk of mothers and morbidity of their infants. Eur.J Clin. Nutr. 1997; 51: 302-7.

51 HKI. Vitamin A capsule distribution; trends in Bangladesh Dhaka: Nutritional Surveillance Project, Helen Keller International, 1996.

52 Bloem MW, Hye A, Wijnroks M, Ralte A, West Jr KP, Sommer A. The role of universal distribution of vitamin A capsules in combating vitamin A deficiency in Bangladesh. Am. J. Epidemiol. 1995; 142: 843-55.

53 BINP. Project Monitoring Report, October 1997. Bangladesh Integrated Nutrition Project, Ministry of Health and Family Welfare, Government of the People's Republic of Bangladesh, 1997.

54 Greiner T. Report to SIDA on Two Different Nutritional Blindness Prevention Programmes in Bangladesh. Uppsala University, Sweden: International Child Health Unit, 1993.

55 Levin HM, Pollitt E, Galloway R, McGuire J. Micronutrient deficiency disorder. In: Jamison DT, Mosley WH, eds Disease Control Priorities in Developing Countries. World Bank, 1991.

56 HKI. Gardens for Bangladesh. Dhaka, Bangladesh: Helen Keller International, 1996.

57 Hussain R, Chowdhuri MA, Quadir A. ABC Study to Assess the Feasibility of Vitamin A Fortification of Sugar and Edible Oil in Bangladesh for Prevention of Blindness. Dhaka: Assistance for Blind Children.

58 Greiner T, Mitra SN. Evaluation of the impact of food-based approach to solving vitamin A deficiency in Bangladesh. Food Nutr. Bull. 1995; 16(3): 193-205. 